\title{
A (InCESSante) busca Pela garantia da CELERIDAde PROCESSUal: POSSIBILIDADES E DESAFIOS
}

The (incessant) search for the procedural celerity guarantee: opportunities and challenges

\section{Gabriela Schneider}

Mestranda em Direito pela Universidade do Vale do Rio dos Sinos - UNISINOS. Pós-Graduada em Direito Penal e Processual pela mesma Instituição. Advogada. E-mail: schd.gabriela@gmail.com

RECEBIDO EM: 31.08 .12

Aprovado EM: 02.12.12

\section{Resumo}

O presente estudo apresentará enfoques referentes ao direito fundamental da "razoável duração do processo", previsto no artigo 5, inc. LXXVIII, da $\mathrm{CF} / 88$, bem como dos princípios dele decorrentes, com enfoque na garantia da celeridade processual. Serão apresentadas breves noções gerais sobre a referida garantia constitucional, destacando a sua real importância no atual Estado Democrático de Direito. Posteriormente, far-se-á uma análise acerca dos principais desafios enfrentados pelo Poder Judiciário em razão da chamada "crise da Justiça", focando nas causas (destacadas como principais) de morosidade processual: demandas repetitivas, o chamado "tempo morto" do processo e o despreparo dos funcionários que atuam no dia-a-dia nos cartórios judiciais. Por fim, será realizada uma análise crítica sobre qual deve ser o limite de interpretação da garantia da celeridade processual, refletindo especificamente sobre as garantias constitucionais da ampla defesa, do contraditório e da fundamentação das decisões, questionando sobre a necessidade e possibilidade de o processo ser (ou não) célere a todo custo. 
Palavras-chave: Processo. Celeridade Processual. Morosidade da justiça. Garantias constitucionais. Estado Democrático de Direito.

\begin{abstract}
The present study focuses on the fundamental right of "reasonable duration of the procedure" referred to in article 5, LXXVIII, of the CF/88, and the principles deriving from it, with a focus on the procedural celerity guarantee. It will present a succinct general notion on this constitutional guarantee, highlighting its importance in the current Democratic State. Afterward, it will examine the main challenges faced by the Judiciary Power with regard to the so-called "justice crisis ", focusing on some causes of the procedural delays, such as: repetitive demands, the "dead time" of the process and the unpreparedness of the people who work day-to-day in the court registries. Finally, it will be accomplished a critical analysis of which should be the limit of interpretation of the guarantee of procedural celerity, reflecting specifically on the constitutional guarantees of the legal defense, the contradictory and the decisions' foundations, questioning the necessity and possibility of the process to be (or not) fast at all costs.
\end{abstract}

Keywords: Process. Procedural celerity guarantee. Delays of Justice. Constitutional guarantees. Democratic State.

SuMÁRIO: Introdução. 1. Breves considerações sobre a "razoável duração do processo". 2. A "crise da justiça": alguns dos principais fatores que ocasionam a morosidade na justiça brasileira. 3. Principais limites impostos a garantia da celeridade processual: ampla defesa, contraditório e fundamentação das decisões judiciais. Conclusão. Referências.

\title{
INTRODUÇÃo
}

Não sendo exclusividade do nosso país, a "crise da Justiça" é um assunto antigo e ainda um dos mais comentados na atualidade brasileira, principalmente quando se fala na morosidade processual. A Emenda Constitucional n $n^{\circ} 45 / 04$ positivou àquilo que era tão esperado, apesar de já possuir apoio anterior em diplomas internacionais: a razoável duração do processo e todos os meios inerentes para garantir a sua celeridade. 
O presente trabalho traz à tona alguns aspectos importantes referentes ao direito fundamental da "razoável duração do processo", previsto no artigo 5", inc. LXXVIII, da CF/88, bem como dos princípios dele derivados, com enfoque na garantia constitucional da celeridade processual. Serão apresentadas noções gerais, possibilidades e desafios decorrentes da referida garantia constitucional, destacando a sua real importância no atual Estado Democrático de Direito.

A primeira parte dedica-se as noções gerais acerca do tempo razoável do processo, demonstrando que o fator tempo, que permeia a noção de processo judicial, "constitui, desde há muito, a mola propulsora do principal motivo da crise da justiça" (TUCCI, 1997, pp. 15-6). A lentidão da Justiça é consensualmente reconhecida como um dos problemas mais graves dos atuais sistemas judiciais, com custos sociais, políticos e econômicos muito elevados.

Diante disto, muito se discute sobre as causas da morosidade do processo. Os desafios são amplos quando se fala em combater a lentidão da justiça. Na segunda parte do estudo, o foco principal se dará nas principais causas de demora processual, com especial destaque para três delas: demandas repetitivas, o chamado "tempo morto" do processo e o despreparo dos funcionários que atuam no dia-a-dia nos cartórios judiciais.

Já na terceira (e última) parte do trabalho será feita uma breve análise (crítica) da "razoável duração do processo", com questionamentos importantes para o Estado Democrático, buscando verificar se existem limites para a garantia da celeridade processual. As garantias fundamentais da ampla defesa, contraditório e fundamentação das decisões serão analisadas e verificar-se-á a incoerência de se fazer uma defesa cega do princípio da celeridade, ou seja: certos cuidados devem ser tomados com a afirmação de que o processo deve ser célere a todo custo.

\section{Breves Considerações sobre a "Razoável duração do Processo"}

Quando se fala em "crise da Justiça" ${ }^{\text {"473 }}$ um dos principais aspectos ressaltados é, sem sombra de dúvidas, a duração dos processos judiciais. Para Moreira $(2004$, p. 2.) tal aspecto não é exclusividade dos brasileiros, sendo o proble-

\footnotetext{
${ }^{473}$ Não tem por objetivo o presente trabalho adentrar nos aspectos específicos referente à crise do Poder Judiciário ou à "crise da Justiça". Entretanto, importante ressaltar que quando se fala em crise, não se pode ingenuamente pensar que apenas o Judiciário é afetado, quando, na verdade, a crise judicial reflete a própria crise do Estado, conforme as lições de Canotilho (1990): "O Estado como produto da modernidade e concebido como instância superior dotada da coação física legítima, no sentido weberiano, está em crise no seu sentido mais estruturalmente profundo: não assegura a ordem, não tem meios para tornar eficazes os instrumentos mais enérgicos do sistema jurídico - as sanções penais; existe uma "dissolução do sistema" a ponto de tornar indefesos os funcionários - em especial os juízes - que guardaram o "sentido de Estado". Aqui, a crise do poder judicial não tem autonomia; é um epifenômeno da crise do Estado”.
} 
ma praticamente universal ${ }^{474}$. A lentidão processual encontra o tempo como o seu grande vilão e é tema de recorrentes críticas (SALDANHA, 2012, p. 244).

A demora na prestação jurisdicional é consensualmente reconhecida como um dos problemas mais graves dos atuais sistemas judiciais, com custos sociais, políticos e econômicos muito elevados (GOMES, 2003, p.12). A capacidade do Poder Judiciário em responder aos seus jurisdicionados à garantia da razoável duração do processo, além de outros dispositivos, com a presteza que lhe impõe, é um grande desafio. (CALHAO, 2007, p. 131)

Não é por menos que o "tempo razoável do processo" encontra-se expresso em diversos textos internacionais, como na Convenção Europeia dos Direitos do Homem - $\mathrm{CEDH}^{475}$, subscrita em Roma, no ano de 1950; e na Convenção Americana de Direitos Humanos, precisamente em seu artigo $8^{\circ}, 1$. :

Toda pessoa terá o direito de ser ouvida, com as devidas garantias e dentro de um prazo razoável, por um juiz ou Tribunal competente, independente e imparcial, estabelecido anteriormente por lei, na apuração de qualquer acusação penal formulada contra ela, ou na determinação de seus direitos e obrigações de caráter civil, trabalhista, fiscal ou de qualquer outra natureza.

NoBrasil, a razoável duração do processo apareceu como direito fundamental através da Emenda Constitucional n ${ }^{\circ} 45 / 2004$, acrescentando o inciso LXXVIII ao artigo $5^{\circ}$ da Constituição Federal. Contudo, "já era permitido sustentar, com anterioridade, esta possibilidade, através do $\S 2^{\circ}$ do art. $5^{\circ}$ da Constituição Federal, que possibilitava à parte alegar em seu benefício à Convenção Americana sobre Direitos Humanos" (GUIMARAES, 2010, pp. 62-3).

Ainda, anteriormente à Emenda $n^{\circ} 45 / 04$, alguns doutrinadores, entre eles Rodrigues (2004, p. 292), sustentavam que a garantia da "razoável duração do processo" já estava implícita na garantia do devido processo legal. O autor afirma

\footnotetext{
${ }^{474}$ Os Estados Unidos, por exemplo, em razão da lentidão processual, encontrou em meios extrajudiciais uma alternativa, com a chamada Alternative Dispute Resolution (ADR).

${ }^{475}$ Artigo 6 ${ }^{\circ}$, 1.: "qualquer pessoa tem direito a que a sua causa seja examinada, equitativa e publicamente, num prazo razoável por um tribunal independente e imparcial, estabelecido pela lei, o qual decidirá, quer sobre a determinação dos seus direitos e obrigações de carácter civil, quer sobre o fundamento de qualquer acusação em matéria penal dirigida contra ela. O julgamento deve ser público, mas o acesso à sala de audiências pode ser proibido à imprensa ou ao público durante a totalidade ou parte do processo, quando a bem da moralidade, da ordem pública ou da segurança nacional numa sociedade democrática, quando os interesses de menores ou a protecção da vida privada das partes no processo o exigirem, ou, na medida julgada estritamente necessária pelo tribunal, quando, em circunstâncias especiais, a publicidade pudesse ser prejudicial para os interesses da justiça”.
} 
que a referida garantia é reconhecida como direito fundamental nos Estados Democráticos, e integra o rol dos direitos humanos, além de consubstanciarse, sobretudo, da efetivação do direito ao processo, "materializado num procedimento regularmente desenvolvido, com imprescindível concretização de todos os seus respectivos corolários, e num prazo razoável".

A celeridade processual, portanto, é um princípio decorrente do direito fundamental a "razoável duração do processo". É indiscutível que todos que ingressam ${ }^{476}$ na busca de uma solução através do Poder Judiciário reclamam por celeridade e, também, efetividade ${ }^{477}$ na entrega da prestação jurisdicional.

De acordo com Rocha (1993, p. 37), a presteza da resposta jurisdicional contém-se no próprio conceito do direito-garantia que a justiça representa e, portanto, não se quer justiça amanhã, quer-se justiça hoje:

A liberdade não pode esperar, porque enquanto a jurisdição não é prestada, ela pode estar sendo afrontada de maneira irreversível; a vida não pode esperar, porque a agressão ao direito à vida pode fazê-la perderse; a igualdade não pode esperar, porque a ofensa a este princípio pode garantir a discriminação e o preconceito; a segurança não espera, pois a tardia garantia que lhe seja prestada pelo Estado terá concretizado o risco por vezes com a só ameaça que torna incertos todos os direitos.

Diante disto é praticamente impossível não surgir o seguinte questionamento: e qual é o tempo razoável de um processo? Baptista (2000, p. 49) quando escreveu sobre a duração e a efetividade do processo, alertou que há a necessidade de se perceber que o conceito de efetividade se reveste de imprecisão, pois, por mais que se dê o sentido de realizabilidade concreta dos direitos submetidos ao Poder Judiciário, nada fica esclarecido com relação ao tempo necessário para que essa efetividade realmente se consolide.

\footnotetext{
476 "O acesso à Justiça pode, portanto, ser encarado como requisito fundamental - o mais básico dos direitos humanos - de um sistema jurídico moderno e igualitário que pretenda garantir, e não apenas proclamar os direitos de todos. [...] O "acesso" não é apenas um direito social fundamental, crescentemente reconhecido; ele é, também necessariamente, o ponto central da moderna processualística. Seu estudo pressupõe um alargamento e aprofundamento dos objetivos e métodos da moderna ciência jurídica”. (CAPPELLETTI; GARTH, 1998, p. 10). Para Dinamarco (1999, p. 283): "o acesso à justiça é, mais do que o ingresso no processo e aos meios que ele oferece, modo de buscar eficientemente, na medida da razão de cada um, situações e bens da vida que por outro caminho não se poderiam obter".

477 Após analisar alguns aspectos do instituto da efetividade, Guimaraes (2010, pp. 79-81) chega à conclusão de que estamos diante de um postulado (e não um princípio ou sobreprincípio), em razão de sua real importância na construção do Estado Democrático de Direito e a sua extensão nas diversas áreas de poder.
} 
A velha frase clichê "cada caso é um caso" parece explicar o sentido do tempo do processo. Sem a intenção de realizar um estudo aprofundado sobre o tema específico, o caráter da razoável duração do processo envolve três critérios principais: a complexidade da questão de fato e de direito discutidas no processo, o comportamento das partes e de seus procuradores e a atuação dos órgãos jurisdicionais ${ }^{478}$. Por ser o tempo razoável do processo algo realmente complexo, respostas objetivas (e com marcos temporais concretos) não parecem ser compatíveis com o atual Estado Democrático de Direito; ou seja, apenas o caso concreto poderá definir o tempo de cada processo.

A questão torna-se um pouco mais complicada quando a morosidade gera a descrença do povo na justiça; o cidadão, quando toma conhecimento da lentidão e dos males do processo (angústias e sofrimento psicológico), se vê desestimulado de recorrer ao Poder Judiciário, podendo esta lentidão transformar o princípio da igualdade processual, na expressão de Calamandrei, em 'coisa irrisória' (LOPES, 2002, p. 274).

Por tudo isso, o direito fundamental à "razoável duração do processo" é de extrema importância, principalmente àqueles princípios que dele decorrem, como o da celeridade processual. Ora, se estes direitos/garantias/princípios são tão importantes ao processo por qual razão há tanta dificuldade em torná-los eficazes? Muitas são as causas relacionadas à morosidade processual que compactuam para a "crise da Justiça". As discussões deste tema são extensas (e não conclusivas) e diversas são as razões apontadas na doutrina para assinalar a demora na prestação jurisdicional.

\section{A "CRISE DA JUSTIÇA": ALGUNS DOS PRINCIPAIS FATORES QUE OCASIONAM A MOROSIDADE NA JUSTIÇA BRASILEIRA}

A luta contra o tempo processual tem sido incansável. A era pósmoderna $^{479}$ exige respostas rápidas, soluções imediatas - o que, sabe-se, nem

\footnotetext{
${ }^{478}$ Critérios estabelecidos a partir de precedentes da Corte Européia de Direitos Humanos. Sobre o assunto ver: TUCCI, José Rogério Cruz. Tempo e processo: uma análise empírica das repercussões do tempo na fenomenologia processual (civil e penal). São Paulo: Revista dos Tribunais, 1997.

${ }^{479} \mathrm{O}$ conceito de pós-modernismo é amplo, polêmico e não unânime. Em passagem de Boaventura de Souza Santos verifica-se a problemática: "Como todas as transições são simultaneamente semi-invisíveis e semicegas, é impossível nomear com exactidão a situação actual. Talvez seja por isso que a designação inadequada de 'pós-moderno' se tornou tão popular. Mas, por essa mesma razão, este termo é autêntico na sua inadequação". (SANTOS, 2001, p. 50). Nas palavras de Bauman (1998, p. 30): "não é em toda parte, porém, que essas condições parecem, hoje, estar
} 
sempre é possível. Diversos estudos já foram realizados na esperança de encontrar as principais causas da morosidade da Justiça, e é neste ponto que se deve ter certo cuidado.

Na visão de Moreira (2004) muitos mitos são sustentados quando se fala em celeridade processual. Um deles é a crença de que a legislação processual (ou os efeitos decorrentes dela) seja a maior responsável pela duração excessiva dos processos. É inegável que os nossos códigos carregam resquícios de um formalismo $^{480}$ exacerbado e é indiscutível que mudanças são necessárias e certamente bem-vindas aos textos infraconstitucionais ${ }^{481}$. Contudo, o que o autor sustenta, é de que a lei, por mais imperfeições que carregue, não pode ocupar o lugar de máximo relevo como responsável pela morosidade da Justiça. (MOREIRA, 2004, p. 4)

Necessário é, de acordo com Santos (2011), ter consciência dos tipos de morosidade que contaminam cada caso e o ideal de celeridade que se persegue, eliminando, desta forma, os atrasos desnecessários. De acordo com o autor, dois tipos de morosidade podem ser identificados: a sistêmica (decorre da sobrecarga de trabalho, excesso de burocracia e positivismo) e a ativa (consiste na interposição de obstáculos para impedir a sequencia normal dos procedimentos, por parte não só de operadores como magistrados, funcionários, advogados, etc.; mas, também, de algumas partes e terceiros envolvidos).

Com relação à morosidade ativa, é importante recordar um dos submitos citados por Moreira (2004, p. 3): ideia ingênua de quem pensa que todos os jurisdicionados clamam, sob quaisquer circunstâncias, pela solução rápida dos litígios. Basta ter algum tipo de experiência forense "para mostrar que, na

prevalecendo: é numa época que Anthony Giddens chama de 'modernidade tardia', Ulrich Beck de 'modernidade reflexiva', Georges Balandier de 'supermodernidade', e que eu tenho preferido (junto com muitos outros) chamar de 'pós-moderna': o tempo em que vivemos agora, na nossa parte do mundo (ou, antes, viver nessa época delimita o que vemos como a nossa parte do mundo). Ainda é importante destacar a lição de Lemert (2000, p. 53): "não se pode provar, afirmei, que o mundo se tornou pós-moderno. Com efeito, um dos pilares centrais das filosofias pós-modernas é que nada pode ser provado, que tudo está aberto a discussão, tudo é mais uma pretensão de verdade que um argumento estável."

${ }^{480}$ De acordo com Oliveira (1997, p. 7), formalismo é a totalidade formal do processo, "compreendendo não só a forma, ou as formalidades, mas especialmente a delimitação dos poderes, faculdades e deveres dos sujeitos processuais, coordenação de sua atividade, ordenação do procedimento e organização do processo, com vistas a que sejam atingidas suas finalidades primordiais".

${ }^{481}$ Cita-se, como exemplo atual, o Projeto de Lei no $8.046 / 2010$, que busca a implementação de um novo Código de Processo Civil brasileiro, o qual se encontra em curso na Câmara dos Deputados. A proposta traz, na sua exposição de motivos, como um dos principais e relevantes aspectos, a efetividade do direito fundamental à razoável duração dos processos: "levou-se em conta o princípio da razoável duração do processo. Afinal a ausência de celeridade, sob certo ângulo, é ausência de justiça”. 
maioria dos casos, o grande desejo de pelo menos um dos litigantes é o de que o feito se prolongue tanto quanto possível".

Já com relação à morosidade sistêmica, muitas são as causas, discutidas na doutrina, que dão ensejo a esta problemática. Dentre os principais fatores que contribuem para que a prestação jurisdicional não seja célere pode-se destacar a escassez de órgãos judiciais, o insuficiente preparo de muitos juízes, bem como o do pessoal de apoio, a defeituosa organização do trabalho, a insuficiente utilização da moderna tecnologia (MOREIRA, 2004, p.4.) - o que corrobora para a existência de "tempo morto" no processo -, e o excesso de causas repetitivas.

Como o presente estudo não tem o objetivo de esgotar o tema - muito pelo contrário, apenas quer-se fomentar o debate que, apesar de antigo, ainda gera discordâncias e anseia por efetivas soluções - apenas três delas (talvez mais importantes na atualidade) serão destacadas: excesso de causas repetitivas, o chamado "tempo morto" dos processos judiciais e a ausência de preparo dos profissionais que atuam na prática.

A conscientização da população aumentou de forma significativa acerca da possibilidade de acesso à justiça. Após a promulgação da Constituição Federal de 1988, em função do amplo rol de direitos proporcionados, observa-se crescente aumento da litigiosidade no Brasil. De acordo com o Banco Nacional de dados do Poder Judiciário, enquanto que em 1990 o Judiciário recebeu 3,6 milhões de processo, já na década de 2000, esse volume rapidamente ultrapassou o patamar de 20 milhões de ações.

Por exemplo, o último relatório realizado pelo Departamento de Pesquisa Judiciária - "Justiça em números"482, do Conselho Nacional de Justiça, demonstrou que ingressaram na Justiça Estadual ${ }^{483}$, em 2010, 17,7 milhões de processos. O grupo dos maiores tribunais formado por São Paulo, Rio de Janeiro, Minas Gerais e Rio Grande do Sul foi responsável por $62 \%$ dos casos novos. No segundo grupo composto por onze tribunais de médio porte ingressaram $28 \%$ dos processos da Justiça Comum ao passo que no terceiro grupo, com doze tribunais, iniciaram apenas $10 \%$ do total de casos novos no período.

A primeira grande conquista do Estado Democrático é justamente a de oferecer a todos uma justiça confiável, independente, imparcial, e dotada de meios

\footnotetext{
482 "O Departamento de Pesquisas Judiciárias do Conselho Nacional de Justiça apresenta o Relatório Justiça em Números 2010, integrante do Sistema de Estatísticas do Poder Judiciário (SIESPJ). Esse importante sistema engloba a coleta e o tratamento de dados que possibilitam abrir, em bases consistentes, a discussão para o entendimento de indicadores orçamentários, administrativos e de litigiosidade da Justiça brasileira". Relatório Justiça em número, 2010. Disponível em: http://www. cnj.jus.br/images/programas/justica-em-numeros/2010/rel_justica_numeros_2010.pdf. Acessado em: 31.07.2012.

${ }^{483}$ Cita-se a Justiça Estadual a título ilustrativo, sendo que a pesquisa também aborda números da Justiça Federal, Justiça do Trabalho, Superior Tribunal do Trabalho, entre outros.
} 
que a faça respeitada e acatada pela sociedade. Cada vez mais pessoas passaram a ir à Justiça e a dela exigir prestações que, de fato, correspondesse à função que as modernas constituições lhe atribuíam, justamente por terem maior consciência de seus direitos à tutela jurisdicional. (THEODORO JR., 2012)

Além de o cidadão estar mais consciente dos seus direitos, existem alguns canais de incentivo à judicialização dos conflitos, tais como: o próprio setor público, a advocacia e a mídia, conforme salientou a pesquisa intitulada "Demandas repetitivas e morosidade na justiça cível brasileira", de iniciativa do Conselho Nacional de Justiça, publicada em julho de $2011^{484}$.

O excesso de demandas repetitivas é uma das principais causas de "congestionamento" do Judiciário brasileiro, contribuindo significativamente para a morosidade da Justiça ${ }^{485}$. O estudo realizado pela pesquisa supracitada identificou as demandas judiciais repetitivas mais comuns, bem como principais temas e teses jurídicas investigadas. Dentre essas ações, foram escolhidos como estudos de caso os temas da "Desaposentação" (Direito previdenciário - Justiça Federal) e de "Contratos bancários" (Direito do consumidor - Justiça Estadual) ${ }^{486}$.

Uma das conclusões da pesquisa foi de que ações de caráter proativo, capitaneadas pelo Poder Judiciário, incluindo o CNJ, são necessárias para o efetivo combate do problema da morosidade, dentre as quais se destacam o aperfeiçoamento da gestão judicial, a legitimação dos mecanismos alternativos de resolução de conflito, a elaboração de políticas de redução e filtro das demandas judiciais e a cooperação interinstitucional com órgãos da Administração Pública (no caso da pesquisa, com relação ao INSS, Ministério da Previdência Social e

\footnotetext{
${ }^{484}$ Para realizar a pesquisa intitulada "Demandas repetitivas e morosidade na justiça cível brasileira" foram selecionadas três instituições: Fundação Getúlio Vargas (FGV-SP), Pontifícia Universidade Católica do Paraná (PUC-PR) e Pontifícia Universidade Católica do Rio Grande do Sul (PUCRS). Apesar de trabalharem a partir do mesmo tema, os estudos dessas instituições apresentaram abordagens e escopos diferentes e complementares. Todo o trabalho de investigação, realizado ao longo de 2010 e que propiciou a análise da morosidade judicial sob diferentes prismas, foi acompanhado pelo Departamento de Pesquisas Judiciárias (DPJ) do Conselho Nacional de Justiça. V. CNJ. Demandas repetitivas e a morosidade na justiça cível brasileira, 2011, p. 5. Disponível em: http://www.cnj.jus.br. Acessado em: 31.07. 2012.

${ }^{485} \mathrm{O}$ projeto do novo Código de Processo Civil (Projeto $\mathrm{n}^{\circ}$ 8.046/2010) disciplina o Incidente de Resolução de Demandas Repetitivas em seus artigos 930 a 941, com inspiração no modelo alemão (Musterverfahren), que consiste na identificação de processos que contenham a mesma questão de direito, que estejam ainda no primeiro grau de jurisdição, para decisão conjunta. Tal incidente é admissível quando identificada, em primeiro grau, controvérsia com potencial de gerar multiplicação expressiva de demandas e o correlato risco da coexistência de decisões conflitantes. V. Exposição de motivos do Projeto 8.046/2010. Disponível em: http://www.senado.gov.br/senado/ novocpc/pdf/Anteprojeto.pdf. Acessado em: 04.08.2012.

${ }^{486}$ Para as visitas in loco, em virtude da grande representatividade processual existente e da existência de sistemas informáticos mais propícios para a coleta de dados, foram selecionados os Tribunais de Justiça de São Paulo e do Rio Grande do Sul; e, também, o Tribunal Regional Federal da 3a Região.
} 
Banco Central) e com instituições privadas ligadas ao maior número de litígios (como por exemplo, os bancos, empresas de telefonia, etc) ${ }^{487}$.

Constatou-se, também, que as causas do aumento de litigiosidade e morosidade estão relacionadas à regulação administrativa e legislativa, que criam ou que restringem o exercício de direitos. $\mathrm{O}$ estudo refere, ainda, que do ponto de vista interno, "as causas estão principalmente relacionadas aos impactos da judicialização dos conflitos, ao gerenciamento do volume de processos, à falta de uniformização das decisões, à gestão de recursos humanos, à organização judiciária e à conduta das partes" ${ }^{488}$.

Outro fator importante que se destaca como causa de aumento da morosidade processual é o chamado "tempo morto" dos processos judiciais. Em 2007, foi realizada uma pesquisa de estudos de casos, pela Fundação Getúlio Vargas, a pedidos da Secretária de Reformas do Judiciário-Ministério da Justiça, intitulada "Análise da Gestão e Funcionamento dos Cartórios Judiciais" ${ }^{489}$, com o principal objetivo de conhecer a organização e o funcionamento de cartórios judiciais e seus efeitos sobre a morosidade da Justiça.

Os dados levantados na pesquisa confirmaram que as rotinas dos cartórios compõem a maior parte do tempo dos processos judiciais. E, enquanto o processo está em cartório, há períodos que podem ser considerados "tempos mortos" $" 490$, ou seja, tempos em que não se pratica nenhum ato necessário à solução do conflito e que, portanto, poderiam ser eliminados ${ }^{491}$.

Após uma análise detalhada (apesar de se tratar de estudos de casos com finalidade exploratória), três grandes tópicos foram conclusivos a respeito da organização e funcionamento dos cartórios estudados: os cartórios judiciais produzem grande impacto na morosidade do processo e no acesso à justiça ${ }^{492}$; paradoxalmente, o cartório é "invisível" como ator do sistema de justiça ${ }^{493}$; a organização e o

\footnotetext{
${ }^{487}$ V. Pesquisa - CNJ. Idem, p. 32.

${ }^{488}$ V. Pesquisa - CNJ. Demandas repetitivas e a morosidade na justiça cível brasileira, 2011, p. 8.

${ }^{489}$ V. Pesquisa - MINISTÉRIO DA JUSTIÇA - Secretaria de Reformas do Poder Judiciário. Análise da Gestão e Funcionamento dos Cartórios Judiciais, 2007. Disponível em: http://portal.mj.gov.br. Acessado em: 30.07.2012.

${ }^{490} \mathrm{O}$ estudo considerou os chamados "tempos mortos" aqueles em que o processo aguarda alguma rotina a ser praticada pelo funcionário (nas pilhas sobre as mesas ou nos escaninhos), bem como os tempos gastos em rotinas que poderiam ser eliminadas se o fluxo de tarefas do cartório fosse racionalizado.

491 As principais causas apontadas como "tempo morto" foram: o tempo do processo em cartório, os tempos de espera, o tempo após sentença, os tempos de publicação e juntada; e o tempo dos procedimentos sumário e ordinário. V. Pesquisa - MINISTÉRIO DA JUSTIÇA - Secretaria de Reformas do Poder Judiciário. Idem, p. 25.

${ }^{492}$ V. Pesquisa - MINISTÉRIO DA JUSTIÇA - Secretaria de Reformas do Poder Judiciário. Ibidem, cap. II, item 2, pp.23-9.

${ }^{493}$ V. Pesquisa - MINISTÉRIO DA JUSTIÇA - Secretaria de Reformas do Poder Judiciário.
} 
funcionamento dos cartórios judiciais são precários ${ }^{494}$. $\mathrm{E}$, apesar de não ter sido apontado isoladamente fatores que gerem melhor ou pior desempenho dos cartórios judiciais estudados, concluiu-se que a interação de três fatores relacionados entre si são determinantes quando do seu funcionamento: relacionamentos pessoais, ambiente de trabalho e organização/ distribuição de tarefas ${ }^{495}$.

Para minimizar o problema da morosidade da Justiça no tocante ao "tempo morto" dos processos, a tecnologia apresenta-se como uma grande aliada. É preciso adaptar-se e adequar-se a era pós-moderna. Não há fuga. Não há mais como aceitar que um processo permaneça tempo excessivo em cartório em razão dos trâmites meramente burocráticos. É necessário, como salienta Guimarães (2010) que exista uma visão de processo, no mínimo, conformada com a realidade.

Os atrasos que se produzem no processo por inobservância dos prazos estabelecidos, em razão de injustificados prolongamentos das etapas mortas que separam a realização de um ato processo de outro, sem que essas dilações dependam da vontade das partes, são vistos à unanimidade como indevidos. (GARCIA, 1987, p. 119)

O implemento de processos eletrônicos, como já se vê, principalmente, nas Justiças Federais e, também, nos Tribunais Superiores, têm contribuído muito para com a celeridade da Justiça. Por exemplo, na Justiça Federal da $4^{\mathrm{a}}$ Região (estados do sul do País), desde o começo de 2010, somente é possível distribuir novas ações pelo meio eletrônico, como o chamado e-proc; ou seja, nenhuma petição é mais recebida em meio físico. Destaca Ataíde (2010) que, neste caso específico, o "tempo morto" do processo, "quando os autos ficam aguardando a prática de determinados atos físicos, como a autuação da petição inicial ou a juntada de documentos, praticamente foi abolido", tornando a prestação jurisdicional mais eficiente.

Contudo, a história vem comprovando de que mudanças pontuais não solucionam os problemas, ao contrário, muitas delas podem agravá-los. Não se pode pensar em mudanças tecnológicas sem o amparo de uma legislação também preparada para recebê-las e vice-versa. O projeto do Novo Código de Processo Civil, por exemplo, poderia (e deveria) ter se preocupado com essas questões, mas ao que parece não o fez.

Com todo o respeito, mas não consigo imaginar que, no processo civil dos próximos 50 anos, "os atos e os termos do processo" continuem sendo "datilografados ou escritos com tinta escura e indelével", como consta

Ibidem, cap. II, item 3, pp.29-41.

${ }^{494}$ V. Pesquisa - MINISTÉRIO DA JUSTIÇA - Secretaria de Reformas do Poder Judiciário. Ibidem, cap. II, item 4, pp. 41-50.

${ }^{495}$ V. Pesquisa - MINISTÉRIO DA JUSTIÇA - Secretaria de Reformas do Poder Judiciário. Ibidem, p 57. 
do art. 164 do projeto, ainda que seja incluída a possibilidade de atos processuais digitados. [...] Da mesma maneira, não consigo conceber que, no processo civil do futuro, continue o escrivão a numerar e rubricar as folhas dos autos, conforme prevê o art. 162 do mesmo projeto, facultando “às partes, aos advogados, aos órgãos do Ministério Público, aos peritos e às testemunhas rubricar as folhas correspondentes aos atos em que intervierem" (art. 162, parágrafo único, do projeto, tal qual o art. 143 do CPC-SP de 1931 e o art. 18 do CPC de 1939). [...] Esses pequenos trechos do projeto de CPC servem para mostrar que a "nova" codificação poderá nascer velha. E o problema não é apenas terminológico. Não basta apenas substituir as palavras (ATAIDE, 2010).

Além disso, não se pode pensar apenas em mudanças tecnológicas, bem como em legislações preparadas para recebê-las, se não há a conscientização (leia-se: preparo) dos servidores que dia-a-dia atuam na prática.

Por exemplo, com relação ao problema de falta de recursos materiais modernos e, mais precisamente, de informatização, há evidências anedóticas de que esta é, às vezes, uma fonte de mais ineficiência no serviço judicial, e não menos. Uma pesquisa realizada no ano de 2007, pelo Ministério da Justiça, junto a cartórios no estado de São Paulo mostrou que a informatização não acompanhada de treinamento da mão de obra, fez com que, em alguns casos, os cartórios não abandonassem a forma tradicional de trabalho (manual e no papel) mesmo depois de se adotar o procedimento eletrônico. Ou seja, por não confiar na informatização ou até mesmo por não saber operá-la, o trabalho restou duplicado. (YEUNG, 2010, pp. 90-1)

É preciso "abrir os olhos" e ampliar os estudos sobre a chamada «crise do Judiciário». Cada vez mais se percebe que a morosidade da justiça pode não ser apenas atribuída a aspectos técnicos. Um dos possíveis fatores é a falta de organização dos cartórios, da estruturação dos processos, da preparação dos profissionais que atuam diariamente nesta estrutura organizacional, etc. É importante lembrar que, via de regra, quem gerencia os cartórios judiciais são os próprios magistrados, os quais, em geral, não possuem conhecimento técnico de administração; podendo, desta forma, a capacidade gerencial ser um sério problema do sistema judicial como um todo.

Salienta Yeung (2010) que a desmotivação dos funcionários somada à falta de aptidão gerencial dos magistrados pode gerar como resultado a grande ineficiência do sistema. Para o problema, algumas soluções apontadas seriam: reduzir ou eliminar as responsabilidades burocráticas dos juízes em seus respectivos tribunais, treinar funcionários com funções de gerência e supervisão para que sejam bons gestores de recursos humanos, e, consequentemente, 
aumentar a motivação e produtividade, além de treinar os funcionários para o uso de equipamento modernos, etc (YEUNG, 2010, pp. 104-108).

Contudo, inexiste uma fórmula de validade universal que possa resolver por inteiro a equação. É preciso combinar estratégias e táticas e deixar de lado o receio de parecermos incoerentes. Para enfermidades diferentes é necessário experimentarmos também remédios diferenciados (MOREIRA, 2004, p. 7).

Como visto, muitas são as causas da morosidade da Justiça, e muito longe se está de encontrar respostas e soluções. A única certeza é de que continuaremos procurando, pois ser moderno, hoje em dia, passou a significar "ser incapaz de parar e ainda menos capaz de ficar parado" (BAUMAN, 2001, p. 37). No entanto, somente com uma imagem tão exata quanto possível da situação atual [realidade] é que saberemos para qual direção deveremos nos mover (MOREIRA, 2004, p. 13).

\section{Principais limites impostos a garantia da Celeridade processual: AMPLA DEFESA, CONTRADITÓRIO E FUNDAMENTAÇÃO DAS DECISÕES JUDICIAIS}

Conforme visto anteriormente existe no atual Estado Democrático uma grande preocupação com o direito fundamental ao "tempo razoável do processo", bem como com os princípios dele decorrentes, com ênfase na celeridade processual. A partir desta premissa, questiona-se: o processo deve ser célere a todo custo?

Uma sociedade democrática não ousaria prescindir de certos interesses e valores necessários à salvaguarda da atividade jurisdicional. Um processo menos célere é por força um processo de empenho garantístico. Dificílimo é pensar [e querer] a excelência em ambos, pois "é pretensão desmedida querer desfrutar ao mesmo tempo o melhor de dois mundos". (MOREIRA, 2004, p. 5)

O princípio da celeridade processual não pode ser visto como essencial quando o que está em jogo são as garantias constitucionais como a da ampla defesa e contraditório (art. 5', inc. LV, da CF/88: "aos litigantes, em processo judicial ou administrativo, e aos acusados em geral são assegurados o contraditório e ampla defesa, com os meios e recursos a ela inerentes"); e da fundamentação das decisões judiciais (art. 93, inc. IX, da CF/88: "todos os julgamentos dos órgãos do Poder Judiciário serão públicos, e fundamentadas todas as decisões, sob pena de nulidade, ...”). A simplicidade $e$ eficácia processuais, para tornar o processo mais célere, não devem acontecer com o sacrifício das garantias fundamentais dos cidadãos.

A fundamentação das decisões, por um lado, é exigência inerente ao Estado Democrático de Direito e, por outro, é instrumento para viabilizar o controle das decisões judiciais e assegurar o exercício do direito de defesa. Neste sentido, também, são válidas as lições de Calamandrei (2000, p. 175): 
[...] A fundamentação das sentenças é certamente uma grande garantia de justiça, quando consegue reproduzir exatamente, como num esboço topográfico, o itinerário lógico que o juiz percorreu para chegar à sua conclusão. Nesse caso, se a conclusão estiver errada, poder-se-á descobrir facilmente, através da fundamentação, em que etapa do seu caminho o juiz perdeu o rumo.

A decisão judicial não é um ato autoritário, um ato que nasce do arbítrio do julgador, daí a necessidade da sua apropriada fundamentaçã $0^{496}$. Além disso, o juiz, de acordo com o artigo 93, inciso IX, da CF, tem responsabilidade política (para) com a sua decisão (STRECK, 2011).

Acredita-se que todos os caminhos percorridos para tentar acelerar o trâmite processual perdem o sentido quando se suprimem quaisquer das garantias processuais constitucionalizadas, dentre as quais, a fundamentação das decisões jurisdicionais. (FERES, 2008, pp. 123-137)

A motivação permite que o controle das decisões judiciais seja de direito, por violação da lei ou defeito de interpretação e de fato, por defeito ou insuficiência de provas ou por explicação inadequada do nexo entre convencimento e provas. (FERRAJOLI, 2006, p. 574)

A celeridade processual, portanto, não pode carregar o rótulo de uma garantia máxima a todo custo, sob pena de as decisões judiciais serem quantificadas ao invés de qualificadas. A motivação das decisões judiciais é pressuposto básico do atual Estado Democrático de Direito. Torna-se inviável creditar à celeridade processual aquilo que ela não pode nos fornecer: a real confiança na tutela jurisdicional ${ }^{497}$.

Com a revolução democrática da justiça a luta não será apenas pela celeridade (quantidade da justiça), mas também pela responsabilidade social (qualidade da justiça). (SANTOS, 2001, p. 27) Já advertia Carnelutti (1958, p. 154): "se a justiça é segura não é rápida, se é rápida não é segura".

A defesa cega da celeridade está indo de encontro ao Estado Democrático de Direito, que exige decisões com qualidade e, quanto melhor o espaço de diálogo entre as partes, existindo maiores oportunidades de participação (com os princípios do contraditório e da ampla defesa sendo respeitados) melhores serão as decisões judiciais. Afinal, a "decisão não se qualifica como justa pelo

\footnotetext{
${ }^{496}$ Importante referência do STF. V. Recurso Extraordinário n 540995. Relator Ministro Menezes Direito, Primeira Turma, julgado em 19.02.2008. DJe-078, divulgado em 30.04.2008; publicado em 20.05.2008.

${ }^{497}$ Moreira (1988, p. 90) acrescenta: "o controle 'extraprocessual' deve ser exercitável, antes de mais nada, pelos jurisdicionados 'in genere', como tais. A sua viabilidade é condição essencial para que, no seio da comunidade, se fortaleça a confiança na tutela jurisdicional - fator inestimável, no Estado de Direito, da coesão social e da solidez das instituições".
} 
critério da rapidez, e se a justiça não se apresentar no processo não se poderá, também, na sentença". (GONÇALVES, 1992, p. 125)

A celeridade processual precisa estar presente em momentos específicos, principalmente para eliminar burocracias do processo. Conforme visto anteriormente, é neste aspecto que diversos devem ser os mecanismos para que se faça valer essa garantia, como o uso de tecnologias adequadas, etc. Salienta Feres (2008, pp. 123-137) que "suprimir das partes procedimentos legais sob o escudo de aumentar a celeridade processual em vez de combater os 'tempos mortos do processo' e preservar seu curso devido é desconsiderar o texto constitucional".

O que se torna intolerável, em nome da celeridade processual, é aceitar quantidades de decisões julgadas apenas para apresentar números, desmerecendo a qualidade e fundamentação que os julgados necessariamente devem apresentar ${ }^{498}$. Como já afirmou Moreira (2004, p. 5): "se uma Justiça lenta demais é decerto uma Justiça má, daí não se segue que uma Justiça muito rápida seja necessariamente uma justiça boa”. Acrescenta, ainda, em continuidade, que "todos devemos querer é que a prestação jurisdicional venha a ser melhor do que é. Se para torná-la melhor é preciso acelerá-la, muito bem: não, contudo, a qualquer preço".

\section{Conclusão}

Atualmente, na chamada era pós-moderna (ou hipermoderna, na leitura de Lipovetsky (2004)), a celeridade permeia as relações humanas e, no Poder Judiciário, não poderia ser diferente. A sociedade clama por uma prestação jurisdicional célere o que, sabe-se, não vem acontecendo, por isso estamos diante da chamada "crise da Justiça" - e muitos são os impactos diante destes fatos.

A importância da garantia da celeridade processual é inquestionável. O direito a "razoável duração do processo" foi insculpido no rol de direitos fundamentais, através da Emenda Constitucional $n^{\circ} 45 / 04$, acrescentando o inciso LXXVIII ao artigo $5^{\circ}$ da Constituição Federal. Tal direito encontra-se previsto, também, em textos internacionais, como na Convenção Europeia dos Direitos do Homem - CEDH, subscrita em Roma, no ano de 1950; e na Convenção Americana de Direitos Humanos.

Contudo, a garantia da celeridade processual, diante da "crise da Justiça", é alvo de diversas críticas e diferentes estudos já foram (e continuam sendo)

\footnotetext{
${ }^{498}$ É importante frisar que não se está afirmando, necessariamente, que quantidade de decisões proferidas não signifique também qualidade das mesmas. Para tanto, seria necessária a realização de uma pesquisa aprofundada no assunto, com análise de casos práticos, etc. Aqui, pretende-se, apenas, fomentar o debate e deixar o registro para que se pense a respeito.
} 
realizados para tentar encontrar efetivas soluções à morosidade processual. Muitas são as causas para a lentidão processual apontadas pela doutrina, entre elas: a escassez de órgãos judiciais, o insuficiente preparo de muitos juízes, bem como o do pessoal de apoio, a defeituosa organização do trabalho, a insuficiente utilização da moderna tecnologia (corroborando para a existência de "tempo morto" no processo) e o excesso de causas repetitivas.

O presente estudo focou em três das principais causas (o excesso de causas repetitivas, o "tempo morto" do processo, e o despreparo dos funcionários que atuam na prática) e tentou demonstrar, principalmente através de pesquisas realizadas por órgãos competentes, que é possível combater a morosidade realizando uma transformação no que se refere a parte "burocrática" do processo. Chegou-se à conclusão, também, de que não são apenas com mudanças pontuais que os problemas se resolverão. É preciso "abrir os olhos" e ampliar os estudos sobre a «crise do Judiciário». É necessário que se combine estratégias e táticas, deixando de lado o receio de parecermos incoerentes; só assim poderemos encontrar o caminho certo para solucionar (ou melhor: amenizar) os problemas decorrentes da demora na prestação jurisdicional.

Em que pese exista uma busca (incessante) pela celeridade processual, em razão da devida seriedade e necessidade que a garantia representa, é importante questionar e refletir se essa garantia deve ou não ser encarada a todo custo.

Não parece viável que o princípio da celeridade processual seja visto como essencial quando o que está em jogo são garantias constitucionais como a da ampla defesa, contraditório (art. $5^{\circ}$, inc. $\mathrm{LV}$, da CF/88) e a da fundamentação das decisões judiciais (art. 93, inc. IX, da CF/88). A simplicidade e eficácia processuais, para tornar o processo mais célere, não devem acontecer com o sacrifício, principalmente, destas garantias fundamentais.

A celeridade deve ser garantida em momentos específicos, especialmente para eliminar burocracias do processo e, neste aspecto, diversos devem ser os mecanismos para que se faça valer essa garantia: como o uso de tecnologias adequadas, qualificação dos profissionais que atuam dia-a-dia nos cartórios judiciais, etc. $\mathrm{O}$ que se deve combater, no atual Estado Democrático de Direito, é a questão ligada à (indevida) supressão de 'partes' processuais legais (que visam, principalmente, garantir a ampla defesa, o contraditório e a motivação das decisões) para garantir, simplesmente, que o processo obtenha a sua razoável duração. 


\section{REFERÊNCIAS}

ATAIDE, Vicente de Paula Junior. O novo $C P C$ : escrito com tinta escura e indelével. Instituto Brasileiro de Administração do Poder Judiciário. IBRAJUS, Revista Online, 2010. Disponível em http://www.ibrajus.org.br.

BAUMAN, Zygmunt. Modernidade Líquida. Rio de Janeiro: Zahar, 2001. , Zygmunt. O malestar da pós-modernidade. Rio de Janeiro: Zahar, 1998.

BRASIL. Constituição da República Federativa do Brasil de 1988.

CALAMANDREI, Piero. Eles, os Juízes, vistos por um advogado. São Paulo: Martins Fontes, 2000.

CALHAO, Antonio Ernani Pedroso. O princípio da eficiência na administração da justiça. São Paulo: RCS Editora, 2007.

CANOTILHO, José Joaquim Gomes. Crise do poder judiciário. In: Anais da XIII Conferência. Nacional da OAB, 1990.

CAPPELletTI, Mauro; GARTH, Bryant. Acesso à justiça. Porto Alegre: Sérgio Antônio Fabris Editor, 1998.

CARNELUTTI, Francesco. Diritto e processo. Napoli, Morano, 1958.

CARVALHO, Kiladare Gonçalves. Direito Constitucional: teoria do Estado e da Constituição - Direito Constitucional positivo. 14. ed. ver. atual e ampl, Belo Horizonte: Del Rey, 2008.

DINAMARCO, Cândido Rangel. A instrumentalidade do processo. 7. ed. São Paulo: Malheiros, 1999.

FERES, Josan Mendes. A fundamentação das decisões judiciais e a celeridade processual. Revista Brasileira de Direito Processual-RBDPro, ano 16, n. 63. Belo Horizonte: Fórum, p.123-137, jul./-set., 2008.

FERRAJOLI. Luigi. Direito e Razão: Teoria do Garantismo Penal. São Paulo: RT, 2006. 
GARCIA, José Antonio Tomé. Proteccion procesal de los derechos humanos ante los tribunales ordinários. Madrid: Montecorvo, 1987.

GOMES, Conceição. O tempo dos Tribunais: um estudo sobre a morosidade da Justiça. Coimbra: Editora Coimbra, 2003.

GUIMARAES, Darci Ribeiro. Da tutela jurisdicional às forma de tutela. Livraria do Advogado, 2010.

LEMERT, Charles. Pós-modernismo não é o que você pensa. São Paulo: Edições Loyola, 2000.

LOPES, Dimas Ferreira. Direito processual na história. Celeridade do processo como garantia constitucional - Estudo histórico-comparativo: Constituições brasileira e espanhola. Belo Horizonte: Mandamentos, 2002.

MINISTÉRIO DA JUSTIÇA - Secretaria de Reformas do Poder Judiciário. Análise da Gestão e Funcionamento dos Cartórios Judiciais, 2007. Disponível em: http://portal.mj.gov.br.

MOREIRA, José Carlos Barbosa. O futuro da justiça: alguns mitos. In Temas de Direito Processual. 8. série. São Paulo: Saraiva, 2004.

, José Carlos Barbosa. A motivação das decisões judiciais como garantia inerente ao Estado de Direito. Temas de Direito Processual. São Paulo: Saraiva, 1988.

OLIVEIRA, Carlos Alberto Álvaro de. Do formalismo no processo civil. São Paulo: Saraiva, 1997.

ROCHA, Cármen Lúcia Antunes. O direito constitucional à jurisdição. In: TEIXEIRA, Sálvio de Figueiredo (Coord.). As garantias do cidadão na justiça. São Paulo: Saraiva, 1993.

RODRIGUES, Clóvis Fedrizzi. Celeridade processual versus segurança jurídica. Revista de Processo. São Paulo, vol. 120, p. 289-299, fev./2004.

SALDANHA, Jania Maria Lopes. Subtancialização e efetividade do processo civil: a sumariedade material da jurisdição - proposta de estabilização da tutela antecipada em relação ao projeto de novo CPC. Curitiba: Juruá, 2012. 
SANTOS, Boaventura de Souza. A crítica da razão indolente: contra o desperdício da experiência. São Paulo: Cortez, 2001.

, Boaventura de Souza. Para uma revolução democrática da justiça. 3 ed. rev. atual e ampl. São Paulo: Cortez, 2011.

SILVA, Ovídio Baptista da. Celeridade versus economia processual. Genesis Revista de Direito Processual Civil. Curitiba, Genesis, vol.15, jan, 2000.

STRECK, Lenio Luiz. Verdade e Consenso: Constituição, Hermenêutica e Teorias Discursivas. 4. ed. São Paulo: Saraiva, 2011.

THEODORO JR., Humberto. Celeridade e efetividade da prestação jurisdicional. Insuficiência da reforma das leis processual. Disponível em: www.abdpc.org.br.

TUCCI, José Rogério Cruz. Tempo e processo: uma análise empírica das repercussões do tempo na fenomenologia processual (civil e penal). São Paulo: Revista dos Tribunais, 1997.

YEUNG, Luciana. Além dos "achismos", do senso comum e das evidências anedóticas: uma análise econômica do judiciário brasileiro. Tese de Doutorado em Economia de Empresas defendida na EESP-FGV. São Paulo: EESP -FGV, 2010. 